\title{
Noninvasive Methods for Monitoring Bear Population Trends
}

The U.S. Geological Survey began a grizzly bear research project in 2009 in the Northern Continental Divide Ecosystem (NCDE) of northwestern Montana. This work uses hair collection and DNA analysis methods similar to those used in the 2004 Northern Divide Grizzly Bear Project. However, instead of producing a snapshot of population size, the objectives of this new work are to estimate population growth rates by collecting hair at natural bear rubs along trails, roads, and fence and power lines. This approach holds promise of providing reliable estimates of population trends in an efficient, costeffective, and unobtrusive way.

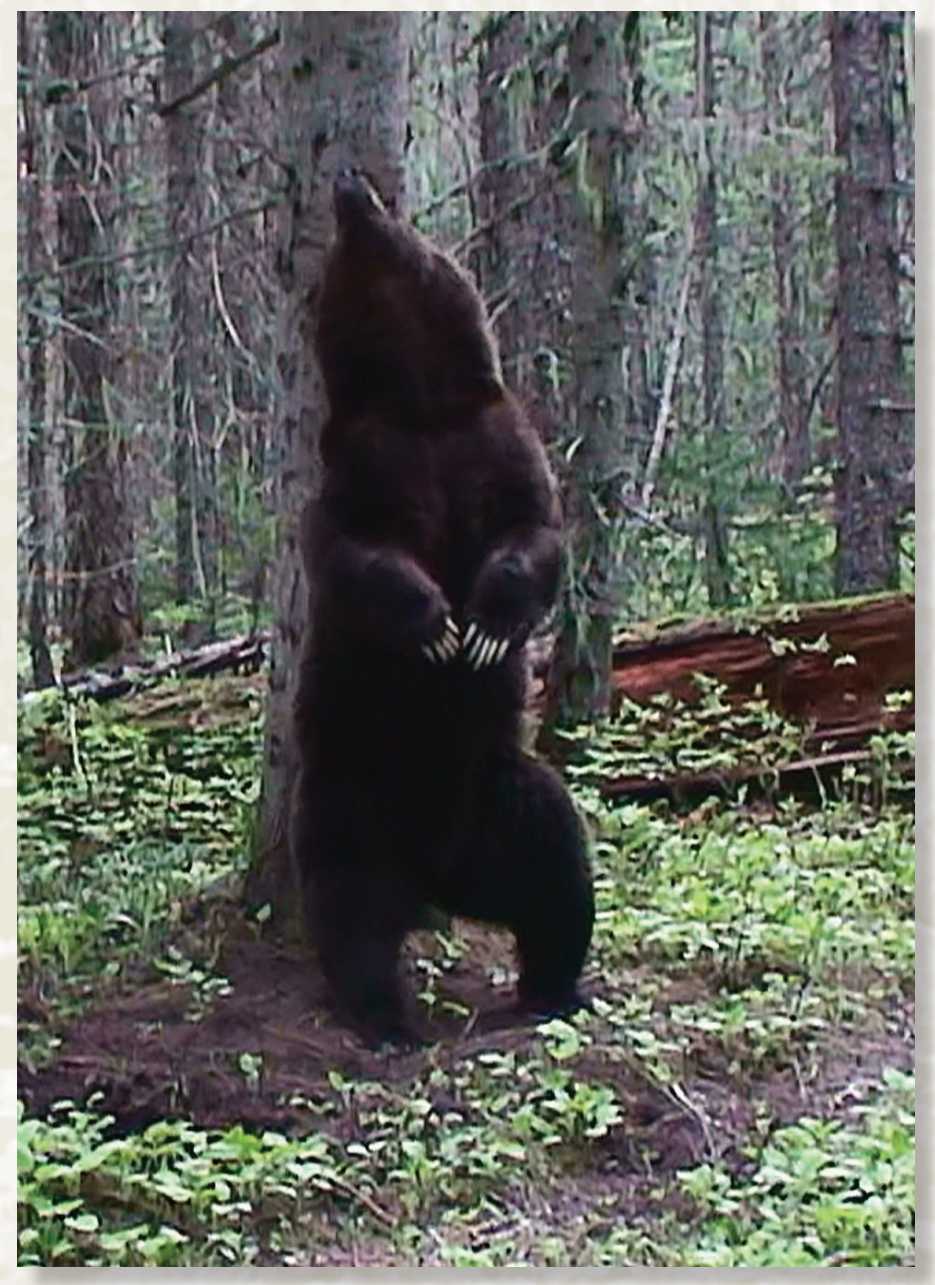

Bear rubs and other passive hair-collection opportunities occur on all types of lands found in the NCDE: forest and prairie, public and private, front and back country. Bear rubs are found by hiking forest trails, roads, and power and fence lines. Short pieces of barbed wire were attached to the rubbed surface to facilitate hair collection at most sites; however, barbless wire is used on trees bumped by pack animals. No lure or attractants were used to attract bears to these sites. Genetic analysis of the hair reveals the species, sex, and individual identity of the bears using rub trees. We use this information in mark-recapture models to estimate population growth and survival rates, along with other valuable information.

\section{Update}

We conducted field work from mid-May into early October in our 8.5-million-acre study area in 2009 . We identified 4,907 bear rubs from which we collected 9,240 bear hair samples. Genetic analysis identified 258 individual grizzlies that had deposited the hair. Field work will continue through 2011. An evaluation of the effectiveness of monitoring bear population trend using this approach will be conducted in 2012.

\begin{tabular}{|l|l|l|l|l|}
\hline \multicolumn{2}{|c|}{ Timeline } & 2009 & 2010 & 2011 \\
\hline Identify/setup bear rubs & & & & \\
\cline { 2 - 5 } & & & \\
\hline $\begin{array}{l}\text { Hair collection } \\
\text { Genetic/data analysis }\end{array}$ & & & & \\
\hline Prepare manuscript & & & & \\
\hline
\end{tabular}

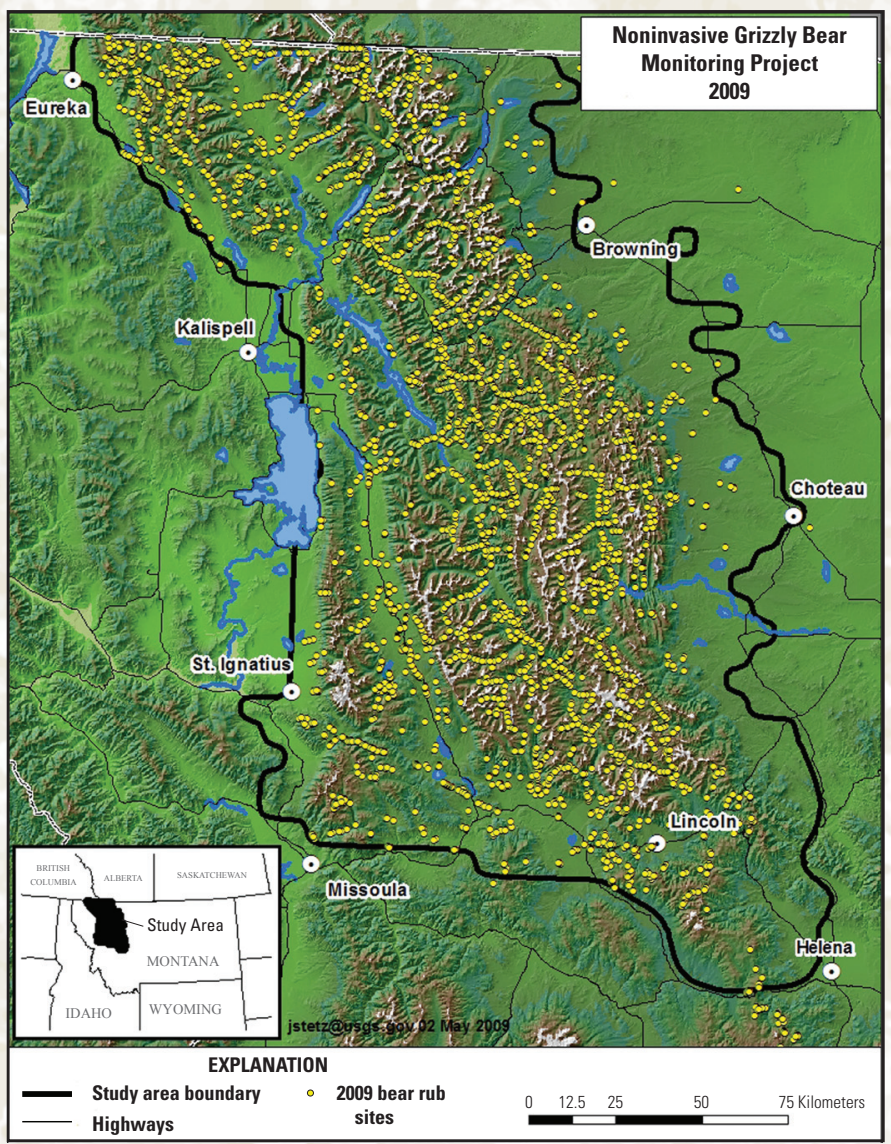




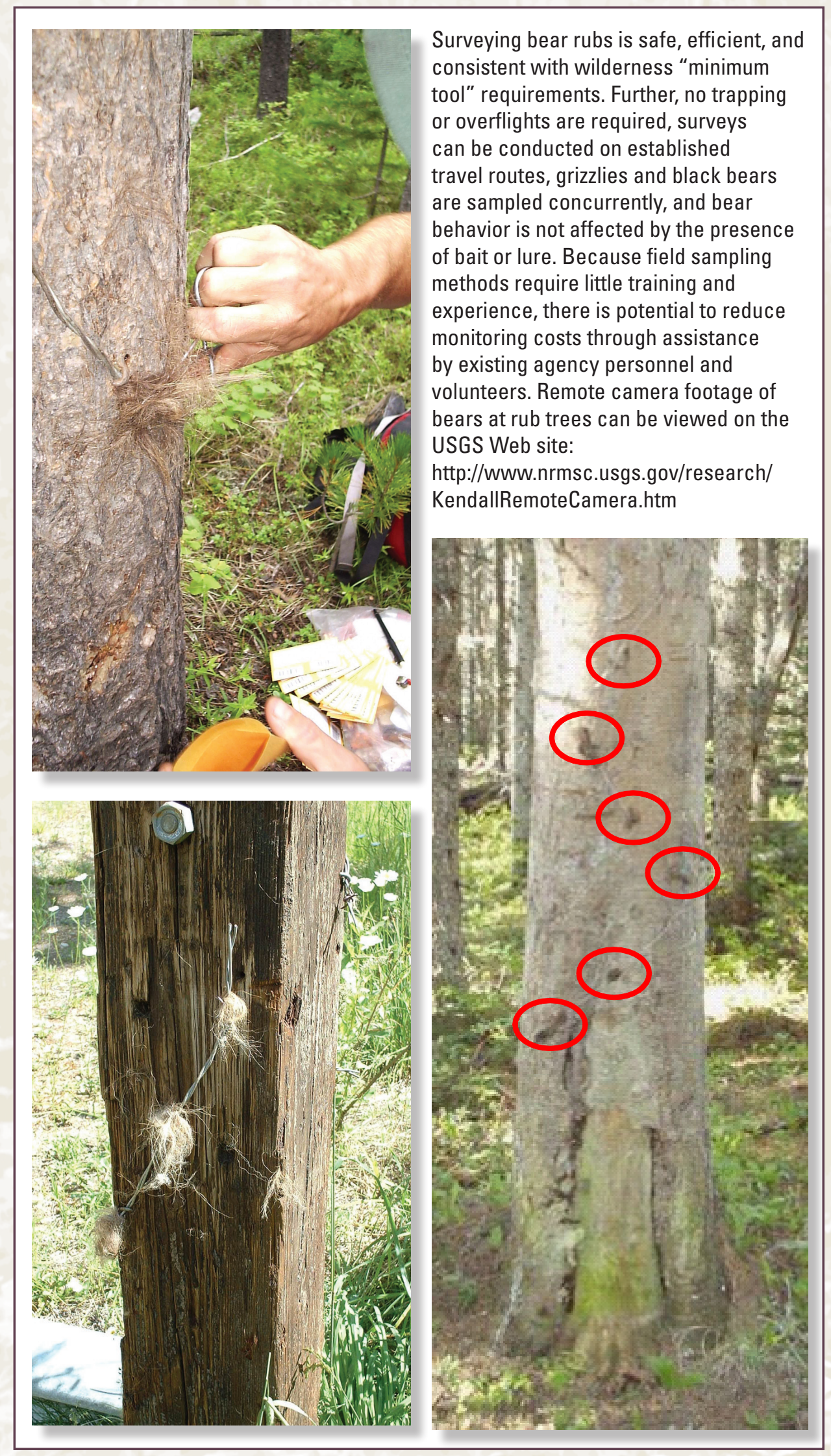

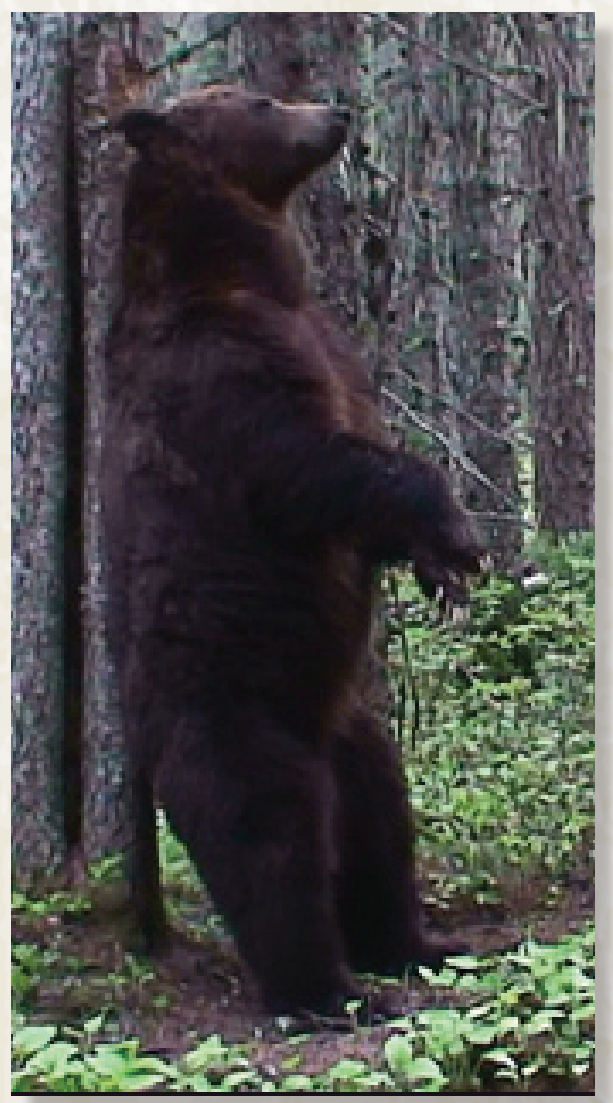

Our previous work demonstrated that collecting hair from bear rubs can sample a large portion of the population. In 2004, nearly 13,000 hair samples were collected from 4,795 bear rubs. From these samples, we detected more than 50 percent of the males and more than 25 percent of the female grizzlies in the population. This was despite not being able to conduct sampling on 20 percent of the NCDE and not sampling in late summer when female rubbing behavior peaks. We can use these detections to look at fine-scale patterns in this population, including changes in how bears are distributed on the landscape, and if there are any barriers to interbreeding (that is, geneflow) within the NCDE. By surveying bear rubs throughout occupied range and over a longer sampling season, we expect to detect even more grizzlies than the 275 individuals detected at bear rubs during 2004 once a sampling network is established. More detections allow us to make more reliable inferences about how this population is faring and assess progress toward recovery.

For more information, please visit the project's Web site: http://www.nrmsc.usgs.gov/research/NGSbear_monitoring.htm
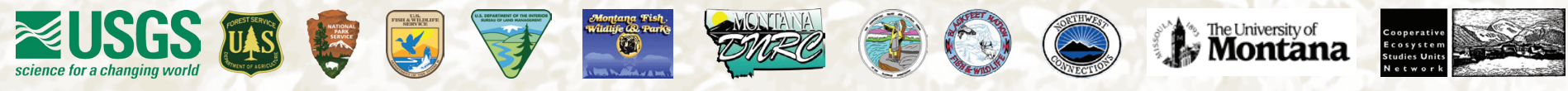